REGARDS

SUR LECONOMIE ALLEMANDE

BULLETIN ECONOMIQUE DU CRAC

\section{Regards sur l'économie allemande}

Bulletin économique du CIRAC

109 | 2013

Varia

\title{
Salaires 2012 : hausse plus forte en RFA qu'en France
}

Isabelle Bourgeois et Raphaël Manseau

\section{(2) OpenEdition}

Édition électronique

URL : http://journals.openedition.org/rea/4564

DOI : $10.4000 /$ rea. 4564

ISSN : 1965-0787

Éditeur

CIRAC

\section{Édition imprimée}

Date de publication : 4 juillet 2013

Pagination : 38

ISSN : 1156-8992

\section{Référence électronique}

Isabelle Bourgeois et Raphaël Manseau, «Salaires 2012 : hausse plus forte en RFA qu'en France »,

Regards sur l'économie allemande [En ligne], 109 | juillet 2013, mis en ligne le 19 juillet 2013, consulté le 15 septembre 2020. URL : http://journals.openedition.org/rea/4564

Ce document a été généré automatiquement le 15 septembre 2020.

(c) CIRAC 


\title{
Salaires 2012 : hausse plus forte en RFA qu'en France
}

\author{
Isabelle Bourgeois et Raphaël Manseau
}

1 En 2012, les salaires de base du secteur privé ont connu une hausse plus forte en Allemagne qu'en France : 2,8 \% contre 2,1\% (après respectivement 2,0\% et 2,2\% en 2011). C'est ce qu'il ressort d'une étude conjointe de l'INSEE et de Destatis. Dans l'Hexagone, l'évolution a été plus homogène; quant au SMIC, il a connu une revalorisation de $3,3 \%$. Outre-Rhin, où il n'existe pas de salaire minimum légal généralisé, la hausse a été plus hétérogène selon les secteurs. Ainsi, les salaires dans l'immobilier n'ont crû que de 1,5\%, tandis que la hausse a été particulièrement forte dans trois filières clés pour l'économie allemande: les transports et l'entreposage $(3,0 \%)$, les services spécialisés, scientifiques et techniques (3,1\%) et l'industrie manufacturière $(3,2 \%)$. Ces hausses, qui se sont poursuivies cette année notamment dans l'industrie des métaux (3\% en moyenne), reflètent «la situation globalement favorable de la conjoncture et du marché de l'emploi dans le secteur des services... et l'importance accordée à la garantie d'emplois fortement rémunérés dans l'industrie exportatrice », en conclut la Bundesbank (rapport de juin 2013). (IB/RM)

France-Allemagne : hausses de salaires mensuels* par secteurs en 2012

\begin{tabular}{|l|l|l|}
\hline (variation annuelle en \%) & Allemagne & France \\
\hline Ensemble du secteur privé & $\mathbf{2 , 8}$ & $\mathbf{2 , 1}$ \\
\hline Industries extractives & 2,1 & 2,3 \\
\hline Industrie manufacturière & 3,2 & 2,4 \\
\hline Energie, approvisionnement en eau et assainissement & 2,8 & 2,1 \\
\hline Construction & 2,4 & 2,0 \\
\hline
\end{tabular}




\begin{tabular}{|l|l|l|}
\hline Commerce ; maintenance et réparation de véhicules automobiles & 2,6 & 2,2 \\
\hline Transports, entreposage & 3,0 & 1,9 \\
\hline Hébergement, restauration & 1,8 & 2,4 \\
\hline Information, communication & 2,2 & 2,0 \\
\hline Finance, assurance & 1,8 & 2,0 \\
\hline Immobilier & 1,5 & 2,1 \\
\hline Activités spécialisées, scientifiques et techniques & 3,1 & 2,1 \\
\hline Autres activités de services & 2,1 & 2,1 \\
\hline PM : indice des prix à la consommation harmonisé (IPCH) & 2,1 & 2,2 \\
\hline
\end{tabular}

Source des données : www.destatis.de/DE/PresseService/Presse/Pressemitteilungen/2013/06/ PD13_201_622.html, et www. insee.fr/fr/indicateurs/ind109/20130618/FR-ALL_2012.pdf. *)

Rémunération du salaire de base (RFA : salaires conventionnels de branche) versé régulièrement hors primes.

\section{INDEX}

Mots-clés : salaire, revenu, comparaison franco-allemande, statistique, emploi, marché du travail 